\title{
Pesquisa Histórica em Administração: a (re)construção identitária da Galeria do Ouvidor em Belo Horizonte (MG)
} \\ Historical Research in Business Administration: the (re)construction \\ of identity of the Gallery of Ouvidor in Belo Horizonte (MG)
}

José Vitor Palhares dos Santos

Mestre em Administração. Professor substituto no Instituto Federal de Minas Gerais, Universidade Federal de Minas Gerais, Belo Horizonte, MG. Brasil.E-mail: titopalhares@hotmail.com

\begin{abstract}
Alexandre de Pádua Carrieri
Doutor em Administração. Professor titular na Universidade Federal de Minas Gerais. Belo Horizonte, MG. Brasil. E-mail: aguiar. paduacarrieri@terra.com.br
\end{abstract}

\section{Verônica Fujise Pereira}

Mestranda em Administração. Centro Federal de Educação Tecnológica de Minas Gerais. Belo Horizonte, MG. Brasil. E-mail: veronicafujise@hotmail.com

\section{Talita Soares Martins}

Graduanda em Administração. Universidade Federal de Minas Gerais. Belo Horizonte, MG. Brasil. E-mail: talysoares@hotmail.com

\section{Resumo}

Recentemente, a história tem ocupado um papel importante na área da Administração, especialmente no campo dos Estudos Organizacionais. Nesse sentido, o objetivo deste trabalho é analisar, por meio da pesquisa histórica, a (re)construção identitária da Galeria do Ouvidor, que foi um dos primeiros centros comerciais construídos em Belo Horizonte e que, atualmente, ainda se destaca entre as principais galerias da cidade. Por meio da pesquisa documental e da análise do discurso de narrativas temáticas de atores que trabalham atualmente na Galeria do Ouvidor, o presente estudo buscou ampliar a compreensão a respeito das identidades da organização desde a sua construção. Os resultados evidenciam que a história deste espaço se divide em diversas fases comerciais e em distintas identidades. Identidades estas que estão ligadas às mercadorias comercializadas na Galeria, as quais estão vinculadas à história da cidade de Belo Horizonte. Entretanto, embora novos clientes e produtos surjam nas diferentes identidades da galeria, permanecem resquícios de fases anteriores. Desse modo, a Galeria do Ouvidor pode ser compreendida, então, como um espelho da capital mineira.

Palavras-chave: Pesquisa Histórica. Identidade. Galeria do Ouvidor.

\section{Abstract}

Recently, the history has occupied an important role in the area of Business Administration, especially in the field of Organizational Studies. In this sense, the purpose of this study is to analyze, through historical research, the (re)construction of identity of the Gallery of Ouvidor, which was one of the first commercial centers built in Belo Horizonte and that currently still stands out among the main galleries of city. Through documentary research and discourse analysis of thematic narratives of actors that working on Gallery of Ouvidor, this study aimed to expand the understanding of the organization's identity since its construction. The results show that the history of this space is divided in several commercial phases, in distinct identities. Identities these that are linked to goods traded in the gallery, which are bonded to the history of the city of Belo Horizonte. However, in spite of new customers and products have appeared in the different identities of the gallery, remain vestiges of previous phases. Thereby, the Gallery of Ouvidor can be understood, then, as a mirror of the state capital.

Keywords: Historical Research. Identity. Gallery of Ouvidor. 


\section{INTRODUÇÃO}

O objetivo deste trabalho é analisar, por meio da pesquisa histórica, a (re)construção identitária da Galeria do Ouvidor, que foi um dos primeiros centros comerciais de Belo Horizonte, sendo considerada, naquela época, um ponto tradicional na confecção de roupas para a elite e a classe média belorizontina (GUIABH, 2013). Por meio da pesquisa documental e também da análise do discurso na vertente francesa de narrativas temáticas de sujeitos que trabalham na Galeria do Ouvidor, busca-se ampliar a compreensão a respeito das identidades da organização, atrelando-as a um determinado contexto histórico e sociocultural.

Este estudo parte da premissa de que o espaço pode se tornar um lugar de identificação dos sujeitos com o seu meio social, ou seja, é a partir das práticas cotidianas que as relações sociais são edificadas. Dessa forma, parte-se do pressuposto de que as práticas de comercialização e os produtos oferecidos nas organizações em diversos períodos foram as bases para a (re)construção identitária da organização, uma vez que há um conjunto de significados que os agentes sociais incorporam e exploram em suas realidades. As identidades das organizações, então, se legitimam na composição da realidade social. Os indivíduos que compõem essa realidade tendem classificar as organizações dentro de categorias sociais, definindo como partes do ambiente. Dessa forma, o sujeito inserido na estrutura organizacional constrói e reconstrói sua identidade a partir da interação com o sistema de significações e valores. A identidade de uma organização é, então, afetada pelos significados culturais que a perpassam, variando de acordo com as situações do dia a dia e a história dos atores organizacionais.

Além disso, também se corrobora com as ideias de Vizeu (2010), Costa, Barros e Martins (2010), Souza e Costa (2013) e Barros e Carrieri (2015), de que a análise dos fenômenos organizacionais deve dar atenção às peculiaridades locais e aos contextos socioculturais específicos, e que isto pode ser alcançado por meio da abordagem histórica. Segundo Coraiola (2012), na Administração, especialmente no campo dos Estudos Organizacionais, as pesquisas que adotam a perspectiva histórica são cada vez mais recorrentes, uma vez que a história possibilita a compreensão de fenômenos organizacionais vigentes.
Desse modo, a escolha deste local de análise se dá não somente pela galeria ser um dos primeiros centros comerciais da cidade de Belo Horizonte sendo considerado um ponto tradicional do comércio que engloba diversas organizações - mas também por também envolver trabalhadores cujas narrativas e experiências cotidianas sobre sua gestão ordinária não são apreciadas pelo mainstream na Administração. Dessa forma, busca-se (re)valorizar as narrativas e experiências de sujeitos comuns (MARTINS, 2008), os saberes locais desqualificados ao longo da história de sujeitos "esquecidos" (BARROS; CARRIERI, 2015) $e$ as identidades de organizações que não são tidas como referência de grandes empresas ou organizações de sucesso na nossa área, mesmo estas sendo um dos principais pontos comerciais da capital mineira, como a Galeria do Ouvidor, que este ano completa 51 anos de existência.

Para tanto, este trabalho está estruturado em seis seções, incluindo esta introdução. Os próximos dois tópicos são referentes ao embasamento teórico que sustentam o artigo, mais precisamente sobre a pesquisa histórica em Administração e os estudos sobre identidade, respectivamente. Na quarta seção são apresentados os caminhos percorridos para a elaboração deste estudo e, em conseguinte, explana-se sobre os resultados e discussões, sobre as histórias e identidades da Galeria do Ouvidor. Por fim, são feitas as considerações finais sobre a pesquisa, com suas limitações e sugestões para estudos posteriores.

\section{A Pesquisa Histórica em AdMINISTRAÇÃo}

Recentemente, a história tem ocupado um papel importante na área da Administração, em especial no campo dos Estudos Organizacionais. De acordo com Clark e Rowlinson (2004), diversas disciplinas das Ciências Sociais têm se apropriado de noções históricas para compreenderem e repensarem seus objetos de estudo, inclusive a Administração, onde o diálogo com a História tem propiciado o surgimento de novas perspectivas para o campo. Para Coraiola (2012), houve, nos últimos anos, uma crescente preocupação por parte dos pesquisadores da área em relação à relevância e influência da História, bem como um anseio 
pelo desenvolvimento de pesquisas históricas para a compreensão dos fenômenos organizacionais.

Vizeu (2010) aponta que a ausência da perspectiva histórica nos estudos organizacionais brasileiros torna problemático, por exemplo, o entendimento sobre as nossas peculiaridades culturais e condições específicas no exercício da gestão. Dessa forma, há vários motivos que expliquem essa aproximação entre a Administração e a pesquisa histórica. Kieser (1994) evidencia que esse diálogo entre as áreas possibilita uma teorização sobre fenômenos organizacionais contemporâneos, uma vez que auxilia na compreensão de problemas referentes às práticas organizacionais. Para Pieranti (2008), o passado compreende uma das formas mais adequadas para se explicar o presente.

Nessa perspectiva, Bedeian (2004) e Jacques (2006) inferem que a imprecisão ou desconhecimento do fenômeno no passado compromete uma análise e compreensão mais aprimorada do seu momento atual. Vizeu (2010) corrobora com os autores ao afirmar que é possível, a partir de uma minuciosa análise da trajetória histórica organizacional, questionar e compreender a realidade organizacional vigente. Outra iniciativa interessante que se deseja realçar neste estudo em relação à contribuição da pesquisa histórica nos estudos organizacionais diz respeito às recentes contribuições sobre as histórias de gestão e as histórias de negócios, como destacado no trabalho de Booth e Rowlinson (2006). Além disso, de acordo com Gomes e Santana (2010, p. 2) e Barros e Carrieri (2015), outro benefício das pesquisas históricas em Administração é o de desvendar os discursos de atores do "passado" ou sujeitos considerados "esquecidos" por não terem suas práticas administrativas reconhecidas na academia, abrangendo novas perspectivas de análise para os estudos organizacionais.

Esse diálogo que tem sido estabelecido entre a História e a Administração, especialmente nos Estudos Organizacionais, é denominado por Clark e Rowlinson (2004) como uma "virada histórica" ou historical turn, movimento já consolidado no exterior (ROWLINSON, 2013) e em processo no Brasil (VIZEU, 2010). Autores como Vizeu (2010) e Coraiola (2012) apontam em seus trabalhos uma divisão analítica nas pesquisas históricas em Administração, divisão esta que não significa em uma exclusão ou complementaridade entre esses estudos, mas que permite alocar o posicionamento do pesquisador e o desenvolvimento de diferentes práticas desse tipo de pesquisa em um conjunto de argumentos para compreender os diversos fenômenos organizacionais analisados sob uma perspectiva histórica. O primeiro conjunto de argumentos se refere à necessidade de se considerar a história como mais uma variável de análise a ser explorada no corpus da pesquisa e, para tanto, deve ser teorizada e analisada empiricamente. Nesse contexto, as organizações são compreendidas como fenômenos historicamente situados e busca-se entender a influência e acontecimentos do passado no desenvolvimento dessas organizações. A segunda perspectiva diz respeito à contribuição da história em fornecer um conjunto de metodologias historiográficas para a análise dos fenômenos organizacionais, como, por exemplo, na utilização de métodos da história oral e pesquisa documental. Já o terceiro conjunto de argumentos considera de forma mais radical o emprego da história na Administração, uma vez que, a partir de uma redefinição epistemológica, condiciona as percepções dos pesquisadores e delineia seus interesses de pesquisa (VIZEU, 2010; CORAIOLA, 2012).

Desse modo, é possível perceber que a História muito tem a contribuir na compreensão dos fenômenos organizacionais contemporâneos, tanto em relação a recursos teóricos quanto metodológicos. De acordo com Gomes e Santana (2010, p. 2),

A teoria organizacional, portanto, não pode dispensar o conhecimento histórico para a compreensão da realidade organizacional. A História pode ajudar a teoria administrativa a localizar-se temporalmente e entender por que se administra de um jeito e não de outro.

Para Vizeu (2010), a investigação acadêmica sob uma ancoragem histórica se torna relevante para os estudos organizacionais brasileiros na medida em que só se é possível compreender satisfatoriamente os fenômenos organizacionais quando se parte de suas referências histórico-culturais específicas, ou seja, a pesquisa histórica em Administração tem ganhado grande destaque, pois torna mais compreensível as atuais realidades organizacionais nacionais, uma vez que possibilita a investigação das especificidades em contextos organizacionais brasileiros.

Ademais, corrobora-se com Vizeu (2010), Costa, Barros e Martins (2010), Souza e Costa (2013) e Barros 
e Carrieri (2015), quando estes pontuam que a análise dos fenômenos organizacionais deve dar atenção às peculiaridades locais e aos contextos socioculturais específicos, e que isto pode ser alcançado por meio da abordagem histórica nos estudos organizacionais. Assim, entende-se que a história é desenvolvida no cotidiano através dos discursos, saberes e práticas sociais (SOUZA; COSTA, 2013). Nesse sentido, nossa investigação permeou as práticas cotidianas de negócio situadas historicamente na Galeria do Ouvidor, a fim de evidenciar suas identidades organizacionais em diversos contextos históricos distintos. Por isso, no tópico seguinte expõe-se algumas considerações acerca do tema da identidade.

\section{Concepções SOBRE IDENTIDADE}

Os estudos sobre a definição e a construção da identidade têm refletido as mudanças de concepção do ser humano como sujeito ao longo da História. A perspectiva de análise evoluiu de núcleo autônomo, permanente e constante, para uma perspectiva dinâmica, de processo em construção (HALL, 2003; BERGER; LUCKMANN, 2005). A questão do estudo sobre identidade se baseia, então, nas visões essencialistas e não-essencialistas, ou seja, na concepção da identidade como coerente e permanente ou como um processo fragmentado e instável, respectivamente (WOODWARD, 2000). No presente artigo adota-se a última perspectiva por entender a identidade como um processo, (re)construída constantemente, sendo assim, dinâmica e instável.

Nesse contexto, percebe-se que a construção da identidade passa pela compreensão da identidade como metamorfose. Ciampa (2005) infere que a realidade está em constante movimento, em constante transformação, e que o fazer é sempre uma atividade no mundo, na interação com os outros. Se o sujeito é algo que ele faz, pode-se dizer que nossa identidade vai se transformando através das nossas práticas e relações sociais estabelecidas com os outros no nosso cotidiano. Assim, a ideia de identidade como metamorfose diz respeito "[...] a gente ir se transformando permanentemente! Somos seres humanos, somos matéria; através da prática, a gente vai se transformando! E transformando o ambiente." (CIAMPA, 2005, p. 111).
Na vida cotidiana, o indivíduo se mostra por meio de seus discursos e suas ações. Por isso, as práticas discursivas tornam-se relevantes na construção identitária do indivíduo, uma vez que é através do discurso que o indivíduo se vê compelido a se constituir como sujeito (SOUZA, 2010). Desse modo, a identidade se constrói no cotidiano, no qual é composto pelas relações de poder dos diversos sujeitos, que constituem suas identidades por meio de práticas do dia a dia que acontecem nos espaços simbólicos em que estão inseridos (CERTEAU, 1994). Por meio das atividades cotidianas, de acordo com Souza (2010), a identidade se (re)constrói e se (re)define. Dessa forma, para compreender a construção da identidade da Galeria do Ouvidor, adotou-se nesta pesquisa a concepção de Souza (2010) e Souza e Carrieri (2012), que articulam este tema às práticas cotidianas e ao discurso, conforme demonstrado na Figura 1:

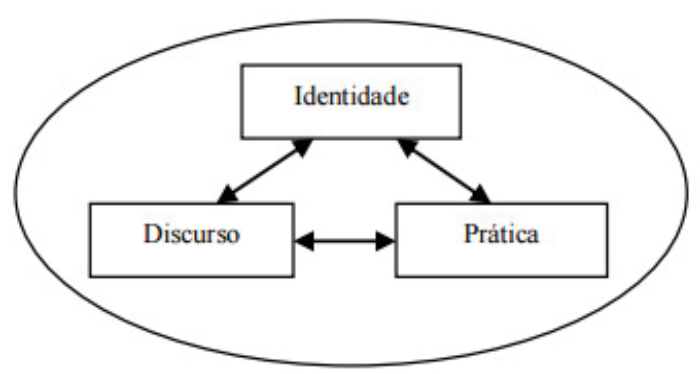

Figura 1: Articulação para a compreensão da identidade Fonte: Souza (2010) e Souza e Carrieri (2012)

Assim, o estudo da identidade perpassaria pela análise das práticas e ações dos sujeitos, por meio dos seus discursos, destacando a relevância da compreensão das práticas no cotidiano dos indivíduos. Contudo, para apreender essas práticas, é preciso levar em consideração os discursos dos indivíduos, uma vez que ele representa parte significante do que ele é (SOUZA; CARRIERI, 2012).

Ademais, é importante destacar que, de acordo com Silva (2000), a identidade e a diferença são o resultado de um processo de produção simbólica e discursiva. Portanto, não é possível compreendê-las fora de um sistema de significação, visto que estes conceitos não são seres da natureza, mas sim, produtos da cultura e dos sistemas simbólicos. Todavia, o autor afirma, baseado na teoria pós-estruturalista de Jacques Derrida, que a linguagem - entendida como sistema de significação - é instável. O processo de significação 
é fundamentalmente indeterminado, incerto e mutante. Assim, a identidade é um atributo em constante mutação, que se define e se redefine de acordo com mudanças culturais, institucionais, simbólicas e de significados. Nesse processo, destaca-se o papel crucial dos discursos no processo de construção da identidade. "Os discursos e os sistemas de representação constroem os lugares a partir dos quais os indivíduos podem se posicionar e a partir dos quais podem falar" (WOODWARD, 2000, p. 17).

Já em relação à identidade organizacional, ressalta-se que, embora haja diferentes perspectivas de estudos sobre identidade - como a individual, a social e a organizacional -, há uma ligação entre elas, uma vez que todas são embasadas no comportamento de indivíduos ou grupos, até mesmo a identidade organizacional, que também é explicada pelo comportamento humano nas organizações (MACHADO, 2003). Albert e Whetten (1985) afirmam que assim como os indivíduos, as organizações também possuem identidades, as quais compreendem as crenças compartilhadas pelos sujeitos sobre o que é central, distintivo e duradouro na organização. Esse processo de fazer com que a organização se torne algo específico na mente de seus integrantes pode ser compreendido como identidade organizacional (SCOTT; LANE, 2000).

Nesse sentido, Saraiva e Duarte (2010) inferem que o conceito de identidade organizacional tornou-se um campo de estudo a partir da década de 1980, por sua diversidade teórica, pluralidade de atores e a influência de fatores internos e externos à organização. Para esses autores, o caminho buscado para se pesquisar as identidades nas organizações deve ser qualitativo e oportunizar a apreensão dos discursos dos sujeitos envolvidos nos processos organizacionais. Sob essa perspectiva, a identidade organizacional pode ser vislumbrada como um resultado pontual, parcial, contextual e temporário de um contínuo processo interminável de reconstrução das narrativas pessoais e organizacionais. Ademais, as identidades organizacionais também podem ser consideradas múltiplas (PRATT; FOREMAN, 2000) e flexíveis e mutáveis (ASFORTH; MAEL, 1996), o que vai depender dos acontecimentos, dos resultados e dos impactos da organização.

\section{Caminhos Percorridos}

A fim de atingir o objetivo proposto neste estudo, trilhou-se os caminhos de uma pesquisa qualitativa (TRIVIÑOS, 1987), com caráter descritivo-exploratório (GIL, 2010). Para Chizzotti (2004), a pesquisa qualitativa permite chegar à essência dos fenômenos estudados através do tratamento e interpretação dos dados, não de maneira isolada, como fatos ou acontecimentos isolados, mas sim, dentro de um contexto onde há uma dinâmica de relações. Como afirmam Denzin e Lincoln (1994), na pesquisa qualitativa o pesquisador tem a liberdade de escolher e combinar as práticas e métodos de pesquisa que se concatenem de maneira mais pertinente ao objeto e ao contexto que se deseja estudar, sendo, portanto, um "bricoleur" (CERTEAU, 1994). Essa posição do pesquisador será útil aos fins propostos por este projeto à medida que convida a utilização de diferentes métodos para dar conta das questões em tela.

Em relação aos procedimentos técnicos, procede-se à análise empírica por meio do estudo multicasos, que consiste na investigação de dois ou mais sujeitos ou objetos através da integração e inter-relação de vários estudos de casos (TRIVIÑOS, 1987). Devido às características culturais especificas do meio no qual se inserem os sujeitos do estudo, e à compreensão da interação destes como um fenômeno social, opta-se pelo estudo de multicasos, uma vez que este fornece a possibilidade de maior penetração na compreensão dos significados expressos pelos sujeitos, e pela interação destes, (con)formando a construção histórica e social de suas realidades.

De acordo com Curado (2001), é interessante que se utilizem, nos estudos com perspectiva histórica em Administração, diversas fontes para a análise dos dados, como a pesquisa documental $e$ as narrativas de história oral, uma vez que, isso feito, facilita na compreensão das características organizacionais, seus processos e atividades administrativas no período estudado. Vizeu (2010) corrobora com a autora ao afirmar que a pesquisa histórica nos Estudos Organizacionais possui princípios de uma historiografia renovada, pois seus autores utilizam e combinam recursos metodológicos alternativos mais adequados para a compreensão dos fenômenos investigados em um cotidiano passado. 
Nesse sentido, busca-se explorar nesta pesquisa o que propõem Barros e Carrieri (2015), uma confluência entre história e cotidiano, a fim de que possa emergir novos olhares nos estudos sobre Administração, como o cotidiano organizacional de pessoas comuns em sua gestão ordinária (CERTEAU, 1994), ou seja, intenta-se evidenciar as identidades históricas do cotidiano organizacional da Galeria do Ouvidor sob a luz da pesquisa documental e da história oral temática com os sujeitos que ali trabalham. A tematização das histórias junto aos entrevistados foi referente aos principais produtos comercializados na galeria desde a sua construção. É importante destacar que Meihy (1996) considera as narrativas temáticas como uma das modalidades da técnica da história oral, além das histórias de vida e da tradição oral. Assim, a utilização de narrativas temáticas proporcionou construir uma cronologia identitária da Ouvidor ligada aos produtos que mais eram comercializados ali em diferentes épocas, desde a construção da galeria até os dias atuais.

Na direção da manutenção da coerência metodológica, operacionaliza-se a investigação por meio de um processo amostral não probabilístico por conveniência, à medida que os membros das organizações aceitaram participar da pesquisa. Além disso, utiliza-se o método "bola de neve" (GIL, 2010) na busca pelos entrevistados, segundo o qual a seleção destes seria construída ao longo do estudo por meio de indicações dos próprios sujeitos de pesquisa. Dessa forma, foi realizada aleatoriamente uma entrevista inicial com um sujeito de pesquisa, que por sua vez, nos indicou outros possíveis entrevistados. Em relação ao número de entrevistas, parte-se das afirmações de Rey (2005) e de Degob e Palassi (2009), os quais inferem que na pesquisa qualitativa não é a quantidade de sujeitos investigados que define a validade dos resultados obtidos, mas sim suas especificidades. Assim, as entrevistas foram interrompidas seguindo o princípio de saturação (PIRES, 2008), quando se observam que novos elementos para subsidiar a teorização não mais seriam alcançados através do campo de pesquisa.

Foram entrevistados sessenta sujeitos de pesquisa que trabalham atualmente na Galeria do Ouvidor. Para o tratamento e análise das narrativas coletadas utiliza-se a vertente francesa da Análise do Discurso (AD), método particularmente adequado para analisar os discursos sobre organizações por levar em consideração aspectos explícitos, implícitos e silenciados
(FIORIN, 2003). Nesse sentido, buscou-se por meio da $\mathrm{AD}$ francesa analisar as particularidades ligadas às condições de produção dos discursos pelos entrevistados, que levam em consideração os protagonistas, o objeto de discurso e os efeitos de sentido do discurso (PÊCHEUX, 1990), tendo como pano de fundo o contexto e a história da Galeria do Ouvidor. Souza et al. (2009) afirmam que o discurso é peça fundamental na compreensão de identidades organizacionais, uma vez que ele fornece determinados sistemas de interpretação da realidade que delineiam identidades às organizações. Desse modo, a $\mathrm{AD}$ francesa seria uma importante ferramenta para extrair do discurso a formação ideológica que o permeia e a identidade organizacional que se relaciona com ela.

Para Carrieri (2001), os discursos estão relacionados a uma ideologia, a uma determinada forma de enxergar o mundo que, em geral, diz o modo como os indivíduos devem ou não agir e, portanto, deve ser visto como uma rede de relações na qual o indivíduo está inserido. Já Pêcheux (1990) afirma que as práticas discursivas seriam a materialização das ideologias presente nas formações sociais, nas interações do homem com o mundo. Desse modo, as práticas discursivas envolvem posicionamentos políticos e ideológicos, sendo atravessadas por relações de poder. Assim, buscou-se analisar o discurso dos entrevistados de forma contextualizada, a partir das condições sócio-históricas em que foi produzido, quem e como o produziu, de que lugar e para quem o foi disseminado, e pretende-se reconstruir as visões de mundo dos atores sociais por meio de uma visão dos sujeitos que presenciaram esses fatos. Além disso, é importante salientar que como nesta pesquisa utilizou-se de diferentes formas para a coleta de dados, a fim de proporcionar maior suporte teórico e empírico ao estudo, foram adotadas a ordenação e a catalogação sistemática dos dados por tipo e ordem cronológica, bem como a supracitada técnica de $\mathrm{AD}$ na vertente francesa para tratamento das narrativas.

\section{HistóRIAS E IDENTIDADES DA GALERIA DO OUVIDOR}

De acordo com os documentos obtidos na Secretaria Municipal de Cultura, Turismo e Esportes da 
Prefeitura de Belo Horizonte, a Galeria do Ouvidor foi inaugurada em março de 1964, a poucos dias do golpe militar, sendo considerada, naquela época, um ponto tradicional na confecção de roupas para a elite e a classe média mineira. Embora sua inauguração não tenha ocorrido em um momento muito propício - devido ao golpe militar - os empresários e lojistas ouvidorenses conseguiram transpor essa barreira e se consolidaram como um dos principais pontos comerciais de Belo Horizonte (PREFEITURA DE BELO HORIZONTE, 2013). Referenciada como o segundo ponto principal de comércio da capital mineira - perdendo somente para o Mercado Central - através da análise de documentos da Secretaria Municipal de Cultura, Turismo e Esportes da Prefeitura de Belo Horizonte sobre a Galeria é possível constatar que ela foi idealizada pela iniciativa de vários empresários que exerceram forte influência na história da cidade, incluindo famílias renomadas como Kubitschek, Mancini, Mahomed, entre outras. Além disso, para a construção da Galeria foi demolido o tradicional Hotel Globo da cidade, onde foi construído um dos primeiros centros comerciais edificado de Belo Horizonte, a Galeria do Ouvidor (GUIABH, 2013; GALERIA DO OUVIDOR, 2014).

Desde seu surgimento, a Galeria do Ouvidor marcou época, já que foi o primeiro lugar de Belo Horizonte a instalar uma escada rolante, causando "frisson" entre a população que frequentava o local, fazendo com que pessoas de cidades do interior viessem à capital somente para conhecer o invento. A origem do seu nome está atrelada à famosa rua da cidade do Rio de Janeiro, Rua do Ouvidor, que possui esse nome devido ao fato de que um ouvidor, oficial da justiça da cidade, chamado Francisco Berquó da Silveira, foi ali morar. Desde então, a rua ficou conhecida em função desse morador. Ademais, a rua também foi apreciada por ser um local de bastante movimento comercial, uma vez que foi palco de grandes inovações, como o primeiro telefone, a primeira vitrine e o primeiro cinema da cidade. Dessa forma, a Galeria do Ouvidor teve seu nome inspirado no cunho comercial que caracterizou a Rua Ouvidor no Rio de Janeiro (NASCIMENTO, 2014).

Atualmente, há na Galeria um total de 353 lojas, sendo elas consideradas, em sua maioria, pequenas empresas familiares, também denominadas de unidades familiares, em que trabalham, aproximadamente, 1.400 funcionários que atendem cerca de 45 mil pessoas por dia. Hoje, com 51 anos, a Galeria tem um pouco de tudo: perfumes, esotéricos, material artístico e para artesanato, souvenires, fantasias, roupas, calçados, embalagens, salões de beleza, sexy shops, conserto de relógios, lojas de perucas, etc. (GUIABH, 2013; GALERIA DO OUVIDOR, 2014).

A história do espaço denominado de Galeria do Ouvidor, contada nas narrativas colhidas, pode ser dividida em diversas fases distintas. Os ouvidorenses dividem estas fases em duas grandes categorias: uma pelo tempo cronológico - o tempo da memória, o tempo corrido de suas vidas, da vida organizada de suas lojas, da galeria; e a outra categoria se dá em relação aos artigos vendidos, pelo conjunto de mercadorias predominantes, expostos nas vitrines. Essas fases podem conviver concomitantemente em um mesmo período de tempo, mas há certa delimitação em relação às mercadorias vendidas em cada época na galeria. Portanto, em cada fase há demarcado o que é central, distintivo e duradouro (ALBERT; WHETTEN, 1985) na organização, delimitando suas identidades.

Desse modo, há a fase dos importados, que ocorreu no final da década de 1960 e início de 1970; a fase das roupas e joias nos anos de 1970; a fase dos chapeados em 1980; e a fase das bijuterias e do artesanato que se iniciou em 1990 e perdura até os dias atuais. Assim, pode-se considerar que a Galeria do Ouvidor possui múltiplas e mutáveis identidades (ASFORTH; MAEL, 1996; PRATT; FOREMAN, 2000), que variam de acordo com as práticas e comportamentos adotados pelos ouvidorenses em determinados momentos (MACHADO, 2003). A seguir, será ilustrada com partes das narrativas dos entrevistados a caracterização dessas fases que delineiam as identidades historicamente situadas na Galeria do Ouvidor.

01 "Veja, era o primeiro shopping de BH, muita gente queria vir para cá. Era uma coisa muito chique mesmo". (E17)

02 "Mas aqui sempre foi assim antigamente, eram lojas de importados, calças, tênis, perfume, desodorantes. O Brasil não fabricava, não tinha e então vinha de Miami, vinha do Paraguai. As vitrines eram uma beleza." (E1)

03 "Porém a história da galeria no final da década de 60 e início da década de 70 é que estavam as grandes lojas, as grandes importadoras de vender calça Lee. Inclusive porque o jeans não era fabricado aqui, era todo importado, e aqui es- 
tavam as importadoras. Depois foram até mesmo proibidas as importações. Mas a galeria já tinha ganho, nesta idade ela já tinha a tradição para se vender roupas e roupa de qualidade." (E33)

Os fragmentos anteriores ilustram um pouco da história do início das atividades comerciais da galeria. Muitos comerciantes queriam estabelecer um escritório, uma loja na galeria, pois este era um espaço de glamour, um lugar "chique", como explicitado no primeiro fragmento. Já os entrevistados 1 e 33 ilustram o primeiro momento vivido no comércio da galeria, onde era comum comercializar produtos importados. Dessa forma, a construção identitária da Galeria do Ouvidor perpassou, na década de 1960, pela fase dos importados, que de certa maneira visavam os consumidores da elite.

Dando continuidade, para muitos ouvidorenses a década de 1970 foram os anos de ouro daquele lugar. Nesse período, o país vivenciou o "Milagre brasileiro" e a conquista do tricampeonato na copa do mundo. Mas também foi a época da ditadura militar, da tortura, da caça aos comunistas, de um "Brasil nunca mais". No contexto da (re)construção identitária da galeria, foi nesse período que houve uma transformação nos produtos comercializados, sendo que os importados cederam lugar às lojas de vestuários, alfaiates, alta costura e sapatarias. Conjuntamente ao vestuário, ganham destaques os apetrechos da moda e, principalmente, as joias e joalherias. Além disso, vale ressaltar que, embora a elite ainda frequentasse a galeria, nesse momento ela também passa a representar oportunidades de consumo para outras classes sociais.

04 "Teve, pelo que eu pude perceber, perceber não, pelo que meu sogro me disse, ela [galeria] teve um ramo muito forte que foi nos anos setenta, muito forte em confecção de roupas." (E11)

05 "Agora muitas lojas modificaram muito a aparência, porque vão evoluindo, às vezes nem é evoluindo, mas trocando, por exemplo, aqui tinha até mais de sete alfaiatarias, tinham um estilo e hoje só tem uma, duas ou três que vivem só de conserto de roupas." (E09)

06 "Aí montamos uma loja na galeria e começamos com aquelas calças de boca larga, boca de sino, como falava né? E foi um sucesso total, que não existia calça pronta. Era o alfaiate e a costureira só pra fazer. Aí foi uma loucura, né?” (E27) 07 "Antigamente era mais roupa fina. Foram os jogadores, o pessoal vinha todo desfilar aqui $e$ tudo e era o auge, porque ela foi o primeiro tipo shopping de BH e hoje ela é mais popular." (E13)

O fragmento 05 apresentado remete à ideia de que o entrevistado percebe não uma evolução que ocorre na galeria, mas principalmente uma transformação histórica e identitária da Galeria, vislumbrada através das práticas cotidianas de comercialização dali, onde as vitrines de importados cedem espaços para as lojas de roupas, para os alfaiates e para a moda. Nesse sentido, a Galeria "dos importados" cede lugar à identidade do artesanato. Mostram também o movimento que começou ocorrer com a entrada de lojas de confecção - representação de marcas de moda - $e$ o produto artesanal das roupas de alfaiatarias. Movimento este que não cessará mais, devido à disputa dos espaços na Galeria entre estas duas vertentes de comércio: o industrial e o artesanal. Este tipo de disputa do produto industrializado, padronizado e do produto artesanal pode ser observado também nos espaços do Mercado Central e da Feira Hippie (CARRIERI et al., 2008; SARAIVA et al., 2014).

Ademais, os fragmentos 06 e 07 nos revelam uma mudança do público da galeria. Em 06, é evidenciado um público mais jovem, representado pelos consumidores das calças boca-de-sino, calças boca larga, que nos anos de 1970 virou sinônimo de juventude. "Esse tipo de calças teve origem nas calças dos marinheiros, que eram cortadas em forma de sino do joelho ao tornozelo, para oferecer maior liberdade de movimento, $e$ nos anos 70 viraram uniforme entre os hippies". Em 07, observa-se uma consequência inclusive da conquista do Tricampeonato mundial de futebol: a galeria começa a ser frequentada por jogadores de futebol. Além disso, este fragmento nos mostra outras transformações que ocorreram na galeria. "Antigamente a roupa era mais fina", e hoje, nos anos setenta já não precisava ser. Antigamente a clientela era a elite, hoje, depois dos jogadores, a galeria tem uma clientela mais popular. A roupa era mais fina, mais bonita, mais chique, depois, quando vieram os jogadores - jovens também - a roupa deixou de ser fina e a identidade da galeria passou a ser atrelada ao consumo das classes populares.

Dando continuidade, é possível notar nos fragmentos 08 e 09 a seguir que não somente a moda era presente na galeria na década de 1970. Como o público jovem começava a frequentá-la, houve, naquele 
momento, uma maior oferta de produtos para eles, como é o caso das lojas de discos, mais precisamente uma loja de um jogador do Cruzeiro, frequentada por jogadores do time e por seustorcedores. Havia também, de acordo com a entrevistada 25, outra loja, que "naturalmente" ficou frequentada pelos jogadores e torcedores do Atlético MG. Essa rivalidade entre os grandes times e torcedores mineiros é encontrada até os dias de hoje em muitas cidades do Estado de Minas Gerais, mas é em Belo Horizonte e em seus diversos espaços que ela é reforçada, uma vez que é a cidade sede dos times. Vale ressaltar também que no fragmento 08 observa-se uma ideia de modernidade: a loja de discos lançava os produtos em $\mathrm{BH}$ ao mesmo tempo em que em outras capitais, como São Paulo e Rio de Janeiro. Eram, então, lançamentos simultâneos, igualando a importância da cidade, da galeria e dos jogadores (do Cruzeiro e do Atlético-MG) a uma aproximação aos grandes centros industriais e econômicos do país.

08 "Havia na galeria espaços para os moços como a loja de discos do goleiro do Cruzeiro, Raul Guilherme Plassman, loja que lançava discos ao mesmo tempo que nas cidades de São Paulo e Rio de Janeiro." (E60)

09 "Só a loja do Raul [Guilherme Plassman]. Era a loja que era frequentada por cruzeirenses, e a Loja X que era frequentada pelos jogadores do Atlético e pelos atleticanos todos. Então é impressionante como que isto sempre fez uma distinção, foi automático, natural. Natural, os cruzeirenses ficavam na Loja do Raul, e tanto os jogadores quanto os torcedores, os jogadores ficavam aqui direto, os jogadores do Cruzeiro porque era a loja do Raul e os jogadores do Atlético e os torcedores aqui na loja dos meus pais. Era muito interessante isto aqui." (E25)

É importante lembrar que a galeria pode ser vista como um arquivo "vivo". Lá se encontram registros - lojas e seus donos - de todos os tempos, de mercadorias, das suas fases, de suas identidades. Como já dito anteriormente, as confecções se tornaram as coqueluches dos anos de 1970. Essa mercadoria ainda é o principal produto de algumas lojas hoje na galeria. Ainda há um alfaiate, ainda há lojas que consertam roupas, as lojas que vendem roupas de cama, lojas que vendem roupas prontas, industriais. Nesse contexto, Rússio (1984) lembra que o uso do novo não elimina o testemunho antigo e que esse antigo se não está presente no espaço, está no tempo, no tempo da memória das pessoas.

10 "Mas a galeria já tinha ganho, nesta idade ela já tinha a tradição para se vender roupas e roupa de qualidade. E isto perdurou provavelmente ai durante a década de setenta e boa parte da década de oitenta que foi quando eu vim para cá porque ali lamentavelmente ai a confecção já estava em declínio em função de vários fatores, mas principalmente pelo advento dos shopping center que começaram a surgir no final da década de setenta". (E06)

De modo geral, para os sujeitos de pesquisa os anos oitenta é marcado pela fase dos produtos chapeados/folhados, peças essas banhadas em ouro e prata que eram comercializadas na galeria. Nesse sentido, há uma nova (re)construção identitária da galeria, que passa a ser identificada nessa década pela venda de chapeados.

11 "Com os Shopping Centers, que começaram a surgir no final da década de 70 e inicio da década de 80, a galeria começou a declinar no setor de confecções, mas ai a galeria é muito versátil, ela começou a crescer em outros setores de folhados, prata, semi-joias, os consertos de roupas permaneceram, a tradição das lanchonetes também." (E11)

12 "Os folhados entraram na galeria depois das joias, era um tipo de imitação, para outro público, mais simples, gente não de bijuterias. Que é prata. A prata já não é tão nobre, não muda de cor, se arrebentar tem jeito de emendar, você faz qualquer coisa com a prata." (E23)

Os fragmentos 11 e 12 enfocam a mudança que ocorreu na galeria na década de oitenta. Destaca-se o fragmento 11 , o qual reifica a galeria como a personagem principal, que se mostra versátil e em uma tentativa de sobreviver como espaço coisificado, porém vivo, buscando outra alternativa econômica (exploração dos folhados) para se concentrar (BERGER; LUCKMAN, 2005). Contudo, é importante lembrar que há a permanência de alguns produtos, como alguns alfaiates, lanchonetes, lojas de roupas, cama e mesa, joias, relógios, etc.

13 "O acessório feminino, então, veja bem, a muIher jamais ela vai deixar de usar uma joia, uma semi-joia. Então, se realmente o poder aquisitivo 
do consumidor, na época caiu, a capacidade de consumo das pessoas, mesmo assim, elas vinham aqui pra comprar uma lembrancinha e assim ela jamais vai deixar de se dar um presente.” (E19) 14 "Não, o artesanato começou bem mesmo depois da prataria. Foi bijuteria e artesanato. Isto por que a Feira cresceu e todo mundo queria vender artesanato lá. Era uma febre, né!” (E44)

Há uma questão bastante curiosa de destacar com o fragmento 13. O entrevistado 19 cita a diminuição do poder aquisitivo dos seus clientes. Ao contextualizar essa fase da galeria com o contexto econômico-histórico e social da época, não só Belo Horizonte, mas todo o Brasil vivenciava uma situação singular, uma vez que os anos de 1980 é conhecido por ser a década da hiperinflação e de reestruturação dos empregos. Dessa forma, toda a conjuntura econômica daquela época foi refletida no poder de compra da população $e$, consequentemente, nos negócios no interior da galeria.

Já nos anos de 1990, as bijuterias e o artesanato ganham mais espaços devido, principalmente, a diminuição do poder aquisitivo da população. Assim, havia a procura por lembrancinhas, nada muito caro, mas que ainda era joia (semi) e não bijuteria. Era, então, uma bijuteria de qualidade, mais refinada. Além disso, é destacado que a crescente oferta de artesanatos na galeria ocorreu por conta do crescimento da Feira Hippie. Portanto, a identidade da Galeria, nessa época, passa a ser atrelada a comercialização de bijuterias e artesanato. Com o passar dos anos, a Galeria do Ouvidor, nome importante que a identifica e a diferencia entre os espaços públicos e comerciais da cidade, ganha a alcunha de Bijuteria Ouvidor, pois, das 272 lojas existentes ali, 250 eram de bijuterias e artesanato, ou seja, $91 \%$ delas, como é possível observar no fragmento a seguir.

15 "Aí foi chegando gente, chegando... não chamava mais Galeria do Ouvidor, chamava Bijuteria Ouvidor, né? Por que em 272 lojas e 250 eram bijuterias. (risos) E foi um sucesso..." (E01)

Com o passar da década de 1990 e com a entrada do novo século, a galeria:

16 "Foi se popularizando e se diversificando em função de produtos e houve esta coisa gostosa, porque aqui hoje é frequentado por uma classe social de A a Z”. (E22)

17 "Foi ficando cada vez mais popular, é mais popular. As vezes um shopping querendo ou não tem muita loja popular também, mas querendo ou não o pessoal que frequenta um shopping é um pessoal de classe média ou de classe média alta, você tem que ter um carro e não é todo bairro que tem um shopping". (E43)

18 "Foi ficando somente o que a gente chama de comércio de sacoleiras. Vem, compra a mercadoria, vai para o interior, igual na Feira [Hippie]." (E50)

A popularização da galeria garantiu àquele espaço a transformação, hoje, em um lugar com história e até mesmo uma identidade. Um lugar frequentado por categorias sociais de A a $Z$ (fragmento 16) ou como evidenciam os entrevistados 43 e 50, frequentado por pessoas de renda mais baixa, um grupo social denominado de popular. Não o grupo social que vai os shoppings, que tem carro, mas sim, aquelas pessoas que não tem carro, andam de ônibus e vão ao centro da cidade. Um grupo social também ligado às cidades menores, do interior, que vem à $\mathrm{BH}$ comprar mercadorias para revender e manter o comércio em suas cidades. Destaca-se o vocábulo "sacoleiras", pois define um tipo de comerciante que é muito comum em relação à Feira Hippie, foi muito comum nas ruas da cidade (antes da retirada dos camelôs) e hoje também está nos Shoppings Populares.

Em sequência, dos anos 2000 adiante:

"A Galeria do Ouvidor figura como um "point" de artigos para fabricação de bijuterias, joalherias, artesanatos, liurarias, vestuários, embalagens, prestação de serviços na área de consertos, contabilidade, advocacia, que podem ser encontrados nos seis pavimentos, nos quais se distribuem 353 unidades comerciais. Para oferecer a confiança e fidelidade aos clientes efregueses, a Galeria conta com aproximadamente 1.400 pessoas, entre empregados, empresários, que atendem uma média de 40 a 45 mil frequentadores diários" (PREFEITURA DE BELO HORIZONTE, 2013).

Além disso, há um movimento interno interessante que se observa no cotidiano daquele espaço. As lojas foram se modificando, o espaço foi se modificando $e$ as mercadorias oferecidas se modificaram, sobretudo, pelas demandas sociais que também começaram a 
ser outras. Há uma galeria diferente, com sua identidade constantemente (re)construída, e para alguns, até mesmo atualizada em termos de comércio e de atendimento aos diferentes gostos dos públicos, como é possível observar a seguir.

19 "Agora sex shopping é mais uma modalidade do mercado atual, eu não tenho nada contra e nem nada a favor não.” (E08)

20 "Eu achei ótimo, eu acho que completou a galeria tendo casa loteria, tendo correio, sex shopping.. eu não sei se deu tanto impacto assim porque realmente está abrindo muito sex shopping aqui." (E01)

Quando se pergunta se a comercialização de produtos das sexshops poderiam vir a constituir uma nova identidade organizacional, ou se haveria uma outra fase de mercadorias na Galeria do Ouvidor, os sujeitos narram que, por enquanto, não observam este fenômeno. O entrevistado E10 ainda completa: "[...] a fase é o seguinte: é o dinheiro do povo que manda", e arrematou dizendo: "o povo está sem dinheiro (risos) [...]". Nesse sentido, atualmente convivem nas lojas das galerias as bijuterias, o artesanato, lojas que ainda exploram as mercadorias das fases anteriores conjuntamente com os novos produtos explorados pelos comerciantes, como as sexshops. Ou seja, a atual identidade da Galeria do Ouvidor mescla aspectos que fizeram parte da (re)construção e constituição da identidade da galeria no seu passado.

\section{Considerações Finais}

Haja vista a importância da Galeria do Ouvidor para a cidade de Belo Horizonte, o objetivo deste estudo foi compreender, por meio da pesquisa histórica, a (re)construção identitária desse espaço. Por meio da utilização de narrativas temáticas com os entrevistados foi possível construir uma cronologia identitária da Ouvidor ligada aos produtos que mais eram comercializados ali em diferentes épocas, desde a construção da galeria até os dias de hoje. Os resultados demonstraram que a história da galeria se divide em diversas fases comerciais, caracterizadas por diferentes identidades. Identidades estas múltiplas e mutáveis, que se diversificam ao longo do tempo, de acordo com a tendência, práticas e comportamentos dos ouvido- renses em cada época. Assim, a história da Galeria do Ouvidor se relaciona, direta ou indiretamente, com a história da cidade.

Além disso, a popularização da galeria garantiu àquele espaço a transformação, hoje, em um lugar com uma identidade, um ambiente frequentado por todas as categorias sociais. Ao fazer uma retrospectiva a partir das narrativas apuradas, houve uma galeria em que a elite ia fazer negócios, comprar importados. Ela foi o primeiro shopping da cidade. As vitrines, muito bonitas, chamavam a atenção da população que ia passear naquele espaço de compras. A identidade da galeria, nessa época, era marcada pela elite e pelo glamour. Contudo, aos poucos as confecções começaram a ser o negócio predominante. A alta costura produto individualizado de alfaiates e costureiras -, as calças jeans e os produtos industriais também ganham espaço na galeria. Isso ocorre devido à tendência de uma moda jovem nos anos de 1970 (estilo Hippie) e da presença constante de jogadores de futebol que estimulavam o público jovem e popular a começar a frequentar aquele espaço. Nessa época, ocorreu uma transformação identitária: a galeria dos importados dá espaço para a galeria do artesanato, do trabalho feito manualmente pelo artesão.

Mas a cidade cresce, muda e, desse modo, a galeria vai se transformando. Novas concorrências (Shoppings Centers) com estacionamento e outros atrativos se instalam em Belo Horizonte, $e$ isso faz com que o público da galeria se modifique. Os produtos mais comercializados passam a ser imitações de joias, uma mercadoria mais acessível. É o momento em que a elite se afasta da Galeria do Ouvidor, que passa a ser frequentada pela classe popular. Além disso, nessa época, o poder aquisitivo do brasileiro caía e os comerciantes da galeria se voltaram, então, para outro público, outros negócios. A Feira Hippie começa a se tornar importante em termos de comércio, mas os "artesãos" da Feira não tinham onde comprar matéria-prima. Assim, os negócios na Ouvidor se tornam especializados em bijuterias, produtos artesanais para suprir as necessidades desses feirantes. Dessa forma, a identidade da galeria passa por esta fase, ganhando até o nome popular de "Bijuteria do Ouvidor".

Entretanto, embora novos produtos e públicos surjam nas diferentes identidades da galeria, sempre ficam resquícios de fases anteriores. A Galeria é, então, 
um espelho da cidade. A forma como Belo Horizonte se (re)organiza no decorrer da história influenciou nas práticas comerciais dos ouvidorenses, e essas práticas comerciais influenciam em como os indivíduos passam a reconhecer e a identificar a Galeria do Ouvidor. A dinâmica da cidade fez com que a elite passasse a frequentar os shoppings centers ao invés das galerias, $e$ os comerciantes desses últimos estabelecimentos se viram obrigados a adaptarem seus negócios as novas demandas e exigências do seu público para a sobrevivência organizacional. Portanto, ao mudar a dinâmica interativa da cidade com o tempo, mudam-se também os consumidores, suas demandas, as práticas comerciais estabelecidas pelos ouvidorenses e as identidades da Galeria.

A partir dos resultados obtidos, tendo em vista a pluralidade das narrativas, a identidade das organizações pode ser compreendida, então, em um contexto histórico, como sendo fluida, um produto em constante mudança e em perpétuo processo de ajuste e reconstrução. Pode ser vista também, dentro de um contexto temporal, como um interminável e contínuo processo de elaboração de novas narrativas pessoais e organizacionais a partir do que já foi vivenciado. $\mathrm{E}$, assim, a perspectiva histórica se mostra importante para a compreensão dessas transformações identitárias dentro da conjuntura atual vivenciada nas e pelas organizações, além de ser uma abordagem relevante e propícia para explorar a história da Administração e dos negócios em geral, em especial sobre suas particularidades locais, ao resgatar especificidades da organização e do contexto no qual ela está inserida, como demonstrado nesse estudo da Galeria do Ouvidor.

Por fim, considera-se como limitação da pesquisa a dificuldade em encontrar documentos referentes à Galeria que acarretassem ao estudo um maior embasamento documental. Para investigações posteriores, propõe-se a utilização da pesquisa histórica como fonte de compreensão dos discursos de outros sujeitos organizacionais marginalizados na área da Administração, como os trabalhadores do Mercado Central, por exemplo, que é o principal ponto de referência em comércio na capital mineira. Além disso, seria interessante analisarem também nesses estabelecimentos comerciais outros aspectos vinculados a Administração, como, por exemplo, as organizações familiares que são formadas ali e as práticas cotidianas de sua gestão ordinária.

\section{Agradecimentos}

Ao $\mathrm{CNPq} e$ à Fapemig pelo suporte técnico $e$ financeiro que permitiu o desenvolvimento desta pesquisa.

\section{REFERÊNCIAS}

ALBERT, S.; WHETTEN, D. A. Organizational identity. In: CUMMINGS, L. L.; STAW, B. M. (Org.). Research in organizational behavior, Greenwich: Jay Press, 1985. p. 263-295.

ASHFORTH, B.; MAEL, F. Organizational identity and strategy as a context for the individual. Strategy Management, [S.I.], n. 13, p. 19-64, 1996.

BARROS, A.; CARRIERI, A. de P. O cotidiano e a história: construindo novos olhares na Administração. Revista de Administração de Empresas, [S.I.], v. 55, n. 2, marçoabril, p. 151-161, 2015.

BEDEIAN, A. G. The gift of professional maturity. Academy of Management Learning and Education, [S.1.], v. 3, n. 1, p. 92-98, 2004.

\section{BERGER, P. L.; LUCKMAN, T. A Construção Social}

da realidade: tratado de sociologia do conhecimento. Petrópolis: Editora Vozes, 2005.

BOOTH, C.; ROWLINSON, M. Management and organizational history: prospects. Management \& Organizational History, [S.I.], v. 1, n. 1, p. 5-30, 2006.

\section{CARRIERI, A. de P. O Fim do "Mundo Telemig": a}

transformação das significações culturais em uma empresa de telecomunicações. 2001. 326 f. Tese (Doutorado em Administração) - Universidade Federal de Minas Gerais, Belo Horizonte, 2001.

CARRIERI, A. P.; SARAIVA, L. A.; PIMENTEL, T. D. A institucionalização da Feira Hippie de Belo Horizonte. Organizações \& Sociedade, [S.I.], v. 15, p. 63-79, 2008. CERTEAU, M. A invenção do cotidiano: artes do fazer. Petrópolis, RJ: Vozes, 1994. 
CHIZZOTTI, A. O cotidiano e as pesquisas em educação. In: FAZENDA, I. (Org.). Novos enfoques da pesquisa educacional. São Paulo: Cortez, 2004.

\section{CIAMPA, A. C. Estória do Severino e a história da}

Severina. São Paulo: Brasiliense, 2005.

CLARK, P.; ROWLINSON, M. The treatment of history in organization studies: towards an 'historic turn'? Business History, [S.l.], v. 46, n. 3, p. 331-352, 2004.

CORAIOLA, D. M. Importância dos arquivos empresariais para a pesquisa histórica em Administração no

Brasil. Cadernos EBAPE.BR, [S.l.], v. 10, n. 2, p. 254 269, 2012.

COSTA, A. S. M.; BARROS, D. F.; MARTINS, P. E. Perspectiva histórica em Administração: novos objetos, novos problemas, novas abordagens. Revista de Administração de Empresas, [S.1.], v. 50, n. 3, p. 288299, 2010.

CURADO, I. B. Pesquisa Historiográfica em

Administração: uma proposta metodológica. In: ENCONTRO ANUAL DA ANPAD, XXV. Campinas, 2001. Anais... São Paulo: ANPAD, 2001.

DEGOB, R.; PALASSI, M. P. Os sentidos da participação dos colaboradores nos projetos e ações sociais dos Correios do Estado do Espírito Santo. Organizações \& Sociedade, [S.I.], v. 16, p. 265-286, 2009.

DENZIN, N. K.; LINCOLN, Y. S. O planejamento da pesquisa qualitativa: teorias e abordagens. Porto Alegre: Artmed, 2006.

FIORIN, J. L. Linguagem e ideologia. 7. ed. São Paulo: Ática, 2003.

GALERIA DO OUVIDOR. Galeria Ouvidor: uma cidade dentro da nossa cidade. [2014]. Disponível em < http:// www.galeriaouvidorbh.com.br/\#quem-somos > . Acesso em: 6 abr. 2014.

GIL, A. C. Como elaborar projetos de pesquisa. 5. ed. São Paulo: Atlas, 2010.

GOMES, A. F; SANTANA, W. G. P. A história oral na análise organizacional: a possível e promissora conversa entre a História e a Administração. Cadernos EBAPE. BR, [S.I.], v. 8, n. 1, art. 1, p. 1-18, 2010.
GUIABH. Galeria do Ouvidor. [2013]. Disponível em <http://www.guiabh.com.br/>. Acesso em: 20 . 2013.

HALL, S. A identidade cultural na pós-modernidade. Rio de Janeiro: DP\&A, 2003.

JACQUES, R. S. History, historiography and organization studies: the challenge and the potential. Management \& Organizational History, [S.1.], v. 1, n. 1, p. 31-49, 2006.

KIESER, A. Why organization theory needs historical analyses. Organization Science, [S.1.], v. 5, p. 608-620, 1994.

MACHADO, H. V. A identidade e o contexto organizacional: perspectivas de análise. Revista de Administração Contemporânea, Curitiba, v. 7, p. 5173, 2003.

MARTINS, J. de S. A sociabilidade do homem simples. São Paulo: Hucitec, 2008.

MEIHY, J. C. S. B. Manual da história oral. São Paulo: Edições Loyola, 1996.

NASCIMENTO, A. "Cidades... mundos em miniatura": as galerias como espaço de consumo e sociabilidade.

E-hum, Belo Horizonte, v. 6, n. 1, p. 1-21, 2013.

PÊCHEUX, M. Análise automática do discurso (AAD-69). In: GADET, F; HAK, T. Por uma análise automática do discurso: uma introdução à obra de Michel Pêcheux. Campinas-SP: Editora da UNICAMP, 1990.

PIERANTI, O. P. A metodologia historiográfica na pesquisa em administração: uma discussão acerca de princípios e de sua aplicabilidade no Brasil contemporâneo. Cadernos EBAPE.BR, [S.l.], v. 6, n. 1, art. 9, p. 1-12, 2008.

PIRES, A. P. Amostragem e pesquisa qualitativa: ensaio teórico e metodológico. In: POUPART, Jean. A pesquisa qualitativa: enfoques epistemológicos e metodológicos. Petrópolis: Vozes, 2008.

PRATT, M. G.; FOREMAN, P. O. Classifying managerial responses to multiple organizational identities. The Academy of Management Review, [S.I.], v. 25, 1, p. 18-42, 2000. 
PREFEITURA DE BELO HORIZONTE. Secretaria Municipal de Cultura, Turismo e Esportes. Galeria do Ouvidor. [2013]. Disponível em: <http://www. belohorizonte.mg.gov.br/local/comercio/galerias/galeriado-ouvidor > . Acesso em: 20 out 2013.

REY, F. G. Pesquisa Qualitativa e subjetividade: os processos de construção da informação. São Paulo: Pioneira Tomson Learning, 2005.

ROWLINSON, M. Management \& organizational history: the continuing historic turn. Management \& Organizational History, [S.I.], v. 8, n. 4, p. 327-328, 2013.

RÚSSIO, W. Texto III. In: ARANTE, Antonio Augusto. Produzindo o passado: estratégias desconstrução do patrimônio cultural. São Paulo: Brasiliense, 1984.

SARAIVA, L. A. S.; CARRIERI, A. P.; SOARES, A. S. Territorialidade e identidade nas organizações: o caso do Mercado Central de Belo Horizonte. Revista de Administração Mackenzie, São Paulo, v. 15, n. 2, p. 97-126, Abr. 2014.

SARAIVA, L. A.; DUARTE, A. C. O. Dimensões da identidade em duas organizações do terceiro setor. In: CARRIERI et. al. (Org.). Identidade nas Organizações. Curitiba: Juruá, 2010.

SCOTT; LANE. A stakeholder approach to organizational identity. Academy of Management Review, [S.I.], v. 25, n. 1, p. 43-62, 2000.

SILVA, T. T. da. A produção social da identidade e da diferença. In: SILVA, T. T. da (Org.). Identidade e diferença. A perspectiva dos Estudos Culturais. Petrópolis: Vozes, 2000, p.73-102.

SOUZA, E. M.; COSTA, A. M. Usos e significados do conhecimento histórico em estudos organizacionais: uma (re)leitura do taylorismo sob a perspectiva do poder disciplinar. Cadernos EBAPE. BR, Rio de Janeiro, v. 11, n. 1, p. 1-15, 2013.

SOUZA, M. M. P. O teatro como forma de se colocar no mundo: a formação de identidades nos Grupos Galpões. 2010. 251 f. Dissertação (Mestrado em Administração) - Universidade Federal de Minas Gerais, Belo Horizonte, 2010.
SOUZA, M. M. P.; CARRIERI, A. P.; FARIA, A. A. M. A projeção da identidade organizacional: um estudo da identidade de uma ferrovia privatizada. In: CARRIERI, A. P. et al. Análise do Discurso em Estudos

Organizacionais. Curitiba: Juruá, 2009. p. 249-275.

SOUZA, M. M. P.; CARRIERI, A. P. Identidades, Práticas Discursivas e os Estudos Organizacionais: Uma proposta teórico-metodológica. Cadernos EBAPE.BR, (FGV), [S.I.], v. 10, p. 40-64, 2012.

\section{TRIVIÑOS, A. R. S. Introdução à Pesquisa em}

Ciências Sociais: Pesquisa Qualitativa em Educação. São Paulo: Atlas, 1987.

VIZEU, F. Potencialidades da análise histórica nos estudos organizacionais brasileiros. Revista de Administração de Empresas, [S.l.], v. 50, n. 1, p. 37-47, 2010.

WOODWARD, K. Identidade e diferença: uma introdução teórica e conceitual. In: SILVA, T. T. (Org.). Identidade e diferença: a perspectiva dos estudos culturais. Petrópolis: Vozes, 2000. 